\title{
HISTÓRIA AMBIENTAL AGRÁRIA: UMA REFLEXÃO DIALÉTICA SOBRE O ESPAÇO RURAL BRASILEIRO
}

\author{
ENVIRONMENTAL AGRARIAN HISTORY: A DIALECTIC REFLECTION \\ ON THE BRAZILIAN RURAL SPACE
}

\section{HISTORIA AMBIENTAL AGRARIA: REFLEXIÓN DIALÉCTICA SOBRE EL ESPACIO RURAL DE BRASIL}

\author{
Adão José Vital da Costa - Universidade Federal de Pelotas - Pelotas - Rio Grande do Sul - Brasil \\ vital.costa@yahoo.com.br
}

José Geraldo Wizniewsky - Universidade Federal de Santa Maria - Santa Maria - Rio Grande do Sul - Brasil

jgwiz@smail.ufsm.br

\begin{abstract}
Resumo
Este artigo trata da contribuição da história ambiental a partir da análise dos seculares ciclos agrários brasileiros, traçando paralelos entre o latifúndio monocultor-exportador, as pequenas unidades de produção alimentar e os impactos socioambientais causados pelos dois modelos, nos tempos e espaços, ao longo do processo civilizatório brasileiro. Trata-se de um questionamento ecológico e humano destinado a ampliar a reflexão agroecológica, tendo como locus o espaço geográfico. Por intermédio do método dialético, este artigo reflete a respeito da essência dos fatos e conflitos econômicos, socioambientais e ético-culturais presentes na história agrária brasileira; analisa ainda os elos políticos que articularam o diferencial cumulativo de capital entre um e outro ciclo agrário, bem como as causas da (des) organização dos sistemas de produção de alimentos.
\end{abstract}

Palavras-chave: história ambiental, agroecossistemas, agroecologia, sustentabilidade.

\section{Abstract}

This article focuses on the environmental history contribution from the analysis of the secular Brazilian agrarian cycles, drawing parallels between the great exporting monoculture large landed rural properties and the small food-producing units, and the consequent impact generated by the two models in both space and time along the Brazilian civilizing process. It consists of an ecological and humane questioning aimed to broaden the agro-ecological reflection, having the geographical space as its locus. Through the dialectic method, this article reflects on the essence of the economic, socio-environmental and ethical-cultural facts and conflicts in the Brazilian agrarian history, analyzing the political links that articulated the distinguishing cumulative capital between agrarian cycles, as well as (dis)organization reasons of the food production systems.

Key words: environmental history, agro-ecosystems, agro-ecology, sustainability.

\section{Resumen}

El artículo trata sobre la contribución de la historia ambiental, a partir del análisis de los seculares ciclos agrarios de Brasil, trazando paralelos entre el latifundio monocultivo-exportador y las pequeñas unidades de producción alimenticia y los impactos socio-ambientales causados por los dos modelos, en el tiempo y en el espacio a lo largo del proceso del desarrollo de la civilización brasileña. Trata del cuestionamiento ecológico y humano destinado a ampliar la reflexión agroecológica, teniendo como lócus el espacio geográfico. Por el método dialéctico, este artículo reflexiona respecto la esencia de los echos y conflictos económicos, socio-ambientales y ético-culturales presentes en la historia agraria de Brasil, analizando los enlaces políticos que articularon la distinta acumulación de capital entre uno y otro ciclo agrario, así también, las causas de la (des) organización de los sistemas de producción de alimentos.

Palabras clave: historia ambiental, agroecosistemas, agroecología, sustentable. 
Introdução

Este artigo analisa os seculares ciclos agrários brasileiros, no que se refere às suas características culturais e socioambientais. É, fundamentalmente, uma proposta de análise das relações das sociedades agrárias, que se formaram na linha do tempo no espaço rural brasileiro, com os seus respectivos agroecossistemas, suas ações e contradições socioambientais. É também um questionamento ecológico e humano, já que se propõe a desvendar em que medida a história ambiental dos ciclos agrários pode contribuir para a reflexão agroecológica no Brasil. A interpretação dos impactos socioambientais das monoculturas, típicos dos latifúndios, ao longo de nossa história, pode revelar a necessidade de refletir, dialeticamente, sobre os benefícios da agroecologia para a gestão dos atuais agroecossistemas e a necessidade urgente de repensar os insustentáveis, imprudentes e imediatistas modelos agrícolas que foram praticados ao longo da história rural brasileira.

A partir desse substrato teórico, entende-se que as atividades agroexportadoras coexistiram e interagiram socioambientalmente com os sistemas de produção agrofamiliar, ou seja, com as pequenas unidades de produção alimentar que se formaram nas franjas dos latifúndios monocultores. Como afirmam Del Priore e Venâncio (2006, p. 102-103),

a história do Brasil foi marcada pela expansão de produtos de exportação, tais como o pau-brasil e/ou o açúcar. Mas, é bom também lembrar que nossa paisagem rural nunca se restringiu à monotonia dessas duas lavouras. Durante a segunda metade do século XVIII nota-se mesmo uma tendência à diversificação. Várias razões colaboraram para isso: o aumento de população e, consequentemente, de produtores e consumidores de alimentos, simultaneamente à crise da produção do ouro e ao declínio do preço intencional do açúcar, exigindo-se alternativas econômicas, assim como o crescimento das atividades comerciais, resultantes dos desdobramentos da revolução industrial europeia chegando ao novo mundo.

Cabe lembrar que a tradicional história dos ciclos econômicos fundamentou a abordagem sobre a organização socioespacial da agricultura brasileira nas formas da produção monocultora-exportadora de base escravista. Por outro lado, desconsiderou as importantes funções desempenhadas pela organização da agricultura de "subsistência", principalmente no que tange à produção de gêneros alimentícios. Nas palavras de Osório (1999, p. 88), 
as populações que se mestiçavam e praticavam a agricultura de subsistência em todas as regiões da América portuguesa, bem como, todas as atividades agrícolas, pecuárias e extrativas cujos produtos abasteciam não só os núcleos urbanos em formação, mas também as áreas responsáveis pelos produtos de exportação. Enfim, desatende-se a existência de um mercado interno de alimentos, abastecedor dos setores exportadores e das cidades.

Uma proposta de interpretação da história ambiental agrária acaba por identificar os fatores que geraram a prevalência intencional da grande propriedade rural, caracterizada pelo sistema escravocrata latifundiário, que explorou de forma predatória os agroecossistemas e restringiu a formação de uma camada social de pequenos cultivadores resilientes, que poderiam se relacionar, agroecologicamente, com suas unidades produtoras de alimentos. A pesquisa dos ciclos que configuraram a geo-história agrária brasileira, voltada para a compressão das comunidades agrárias, suas múltiplas manifestações culturais e suas interconexões territoriais é considerada relevante para o avanço do conhecimento sobre a agricultura de base familiar. Nesse sentido, além de contribuir para o entendimento dos problemas e conflitos econômicos e socioambientais presentes no espaço agrário brasileiro, a história ambiental dos ciclos agrários no Brasil pode auxiliar no desenho das políticas públicas voltadas para a agricultura familiar de base agroecológica, conciliando justiça social, equidade econômica e valorização da diversidade ambiental e cultural.

\section{A contribuição da história ambiental para a análise dos agroecosistemas}

A história ambiental dedica-se a pesquisar as alterações voluntárias ou forçadas nos sistemas produtivos e a complexidade de seus resultados para as comunidades humanas, em conexão com seus respectivos territórios. Ao se defrontarem com esses desafios, os historiadores ambientais lançam mão da interdisciplinaridade para melhor compreender a interação das inúmeras culturas humanas, suas especificidades e diversidades, em relação às respectivas geografias. Precisam compreender o metabolismo agroecossistêmico para avaliar os impactos antrópicos sobre os ecossistemas, bem como as possibilidades e restrições dos processos culturais de adaptabilidade humana a eles. No caso do Brasil, são flagrantes os impactos socioambientais provocados pela organização histórica do espaço agrário. Como diz Martinez : 
No Brasil a palavra “devastação” é recorrente tanto na literatura quanto na bibliografia agronômica, jurídica e administrativa. Marca presença também, na nossa historiografia, particularmente a da primeira metade do século XX. A agricultura do tipo monocultura, como a cana-de-açúcar, é apontada como o principal vetor de ocupação territorial e de supressão de cobertura vegetal no país. No estado de São Paulo, o café responde pela acentuação da curva de desmatamento a partir de 1850. (Martinez, 2006, p. 56)

Dessa maneira, desenhou-se uma estrutura de produção que envolvia natureza e relações de trabalho, que concentrava riqueza na "metrópole" e degradava socioambientalmente a "colônia”. A esse respeito, Zea (1987, p. 275-276) afirma:

Dominar a natureza: esse desejo do homem não conhece limites e o impulsiona a um desejo completamente ilimitado de expansão, no sentido geográfico, sobre o mundo... Terras plenas de riquezas, que esperam esse homem para que ele as explore e faça delas o instrumento de um desenvolvimento sempre insatisfeito... E gere em função dessa ideia do homem, bem como de suas necessidades jamais satisfeitas, que o mundo ocidental se estenderá sobre o resto do planeta. É assim que continentes inteiros virão a ser considerados como propriedades daqueles que deles se apoderaram... É ai que se originam os grandes conflitos do século XX. A busca jamais satisfeita de um desenvolvimento levado ao infinito será a fonte de uma dupla alienação do homem. Uma alienação colonial, horizontal, que transforma outros homens em instrumentos de trabalho. E uma alienação interna, vertical, que acomete o próprio manipulador.

Em sua obra Um sopro de destruição (2002), o historiador ambiental Pádua abordou o pensamento político e crítico ambiental brasileiro nos períodos compreendidos entre 1786 e 1888. No que se refere à percepção sobre a destruição ambiental por parte dos pensadores analisados, que defendiam o ambiente natural naquele momento histórico, afirma o autor:

Os pensadores aqui analisados, de maneira geral, não defenderam o ambiente natural com base em sentimentos de simpatia pelo seu valor intrínseco, seja em sentido estético, ético ou espiritual, mas sim devido à sua importância para a construção nacional. Os recursos naturais constituíam o grande trunfo para o progresso futuro do país, devendo ser utilizados de forma inteligente e cuidadosa. A destruição e o desperdício dos mesmos eram considerados uma espécie de crime histórico, que deveria ser duramente combatido. $\mathrm{O}$ valor do mundo natural, dessa forma repousava principalmente na sua importância econômica e política. A degradação do território derivava de práticas tecnológicas e sociais rudimentares, originadas 
do passado colonial. A grande panaceia para estabelecer a sanidade ambiental da economia brasileira, após séculos de colonialismo predatório, estava na modernização tecnológica e operacional do sistema produtivo e das instituições sociais. A destruição do ambiente natural não era entendida como um "preço do progresso", como na visão hoje dominante, mas sim como um "preço do atraso". (Pádua, 2002, p. 13)

Neste começo de século, percebemos uma grande demanda social pela pesquisa histórico-ambiental. Os motivos dessa valorização devem-se não apenas à forte militância dos cientistas (ecólogos, geógrafos, agrônomos, biólogos, entre outros) que se esforçam para encontrar estratégias de regeneração dos ecossistemas, ou do esforço dos pesquisadores que procuram restaurar e preservar o patrimônio histórico (historiadores, arqueólogos, antropólogos, arquitetos, artistas plásticos, entre outros), mas também ao acentuado interesse de expressivas parcelas da sociedade brasileira e global em conhecer e interpretar os ciclos históricos para melhor compreenderem o presente e melhor prepararem-se para os cenários socioambientais futuros.

A sociedade e a economia brasileira, na percepção de Prado Jr., estruturaram-se em razão do comércio exterior:

Se vamos à essência de nossa formação veremos que na realidade nos constituímos para fornecer açúcar, tabaco, alguns outros gêneros; mais tarde, ouro e diamante; depois algodão, e em seguida café, para o comércio europeu. Nada mais que isto. É com tal objetivo, objetivo exterior, voltado para fora do país e sem atenção a considerações que não fosse o interesse daquele comércio, que se organizarão a sociedade e a economia brasileira. Tudo se disporá naquele sentido: a estrutura social, bem como as atividades do país. Virá o branco europeu para especular, realizar um negócio; inverterá seus cabedais e recrutará a mão-de-obra de que precisa: indígenas ou negros importados. Com tais elementos articulados numa organização puramente produtora, mercantil, constituir-se-á a colônia brasileira. Este início cujo caráter manter-se-á dominante através dos séculos de formação brasileira gravar-se-á profunda e totalmente nas feições e na vida do país. (Prado Jr., 1970, p. 23)

As concepções de Prado Jr. sobre nossas origens históricas e socioeconômicas continuam atuais. Esta herança colonial é tão arraigada nos gestores públicos que no ano de 2007, ante a incapacidade de sanar o problema da fome de cerca de dez por cento da população brasileira, a política agrícola priorizou a expansão da produção de agrocombustíveis 
para, posteriormente, atender à demanda externa internacional. Por sua vez, Sérgio Buarque de Holanda, em sua obra Raízes do Brasil (2007), destaca a importância de conhecermos a história ambiental brasileira para não repetirmos as mesmas escolhas equivocadas quando da elaboração de projetos nacionais de desenvolvimento da agricultura. Segundo o autor, "A tentativa de implantação da cultura europeia em extenso território, dotado de condições naturais, se não diversas, largamente estranhas à sua tradição milenar, é, nas origens da sociedade brasileira, o fato dominante e mais rico em consequências" (Holanda, 2007, p. 31).

O historiador ambiental é um intérprete dos quadros de recursos naturais e das diferentes respostas dadas a eles pelos processos civilizatórios. Se a tradicional, oficial e conservadora história exalta os feitos dos "donos do poder" sem questionar os custos socioambientais de tais feitos, a história ambiental preocupa-se com os impactos ambientais e as consequências sobre a sociedade como um todo. Nas palavras do agrônomo Vivan (1988, p. 20-21),

a história também pode ser lida na observação atual e na recuperação de dados históricos dos desertos, florestas e estepes por onde passaram as civilizações. Buscando significados a partir das evidências da história podemos afirmar que o bom censo em relação ao manejo dos recursos naturais não foi a regra. Pelo contrário, foram frequentemente suplantados pela insensatez, pela sede psicótica por poder e acumulação material. Enfim, é preciso aprender com a história. É consternador aceitar que discursos inflamados dados e evidências, e inclusive leis especificas não foram suficiente para evitar as catástrofes ambientais e sociais que já aconteceram na história.

Embora conservadora história oficial exalte os "feitos" dos "donos do poder”, é possível resgatar uma outra história: a história do massacre da natureza e da degradação das comunidades humanas que, despojadas dos seus recursos naturais, engrossam as fileiras dos espoliados, dos esquecidos, dos desesperançados. Mas é preciso identificar as incoerências das práticas agrícolas insustentáveis para resgatar possibilidades e apontar caminhos comprometidos com a regeneração dos agroecossistemas e a preservação dos grupos humanos que foram e continuam sendo alvos de extermínios. Ao caminharmos pelo túnel do tempo, encontramos dados históricos que nos permitem fazer a reconstituição histórica e ambiental de sociedades e agroecossistemas no Brasil. A esse respeito, diz Lambert: 
Mas a grande propriedade é instável; dedicadas à cultura do café ou do algodão, as plantações esgotam-se rapidamente; em outras regiões do Brasil, as plantações cansadas subsistem e a população que reluta em abandoná-las, vegeta na semiociosidade. No estado de São Paulo, a grande fazenda exaurida tem que se mudar, mas, ao mesmo tempo em que perde o valor, em virtude do esgotamento da terra para plantações de produtos de exportação, a qualidade dos meios de transporte e a existência de grandes centros urbanos de consumo conferem-lhe novo valor para abastecimento da cidade. Laticínios, aves, cereais e toda a fonte de culturas diversas, fazem surgir pequenas propriedades familiares e ao mesmo tempo em que a grande propriedade vai procurar no oeste novas terras, que lhe dão lucro tanto loteando quanto explorando, as zonas que ele abandona vão-se afastando das velhas estruturas coloniais. (Lambert, 1967, p. 121-122)

Se por um lado a história ambiental revela inúmeros exemplos de caos socioambiental que ocorreram em sociedades estruturadas politicamente de maneira centralizada e autoritária, com fortes mecanismos de controle social do patrimônio natural "coletivo", por outro lado ela é rica em exemplos de práticas sustentáveis relacionadas a grupos que conseguem estabelecer sua existência baseada em parâmetros de qualidade de vida, às margens do poder central. Questionado sobre quais eram as lições que o mundo moderno poderia aprender com as "sociedades primitivas", o antropólogo Lévi-Strauss afirmou:

Antes de mais nada, uma lição de sabedoria. O estudo dessas sociedades ensina-nos que, para os humanos, há muitas maneiras de viver em comunidade. Que a forma que nós escolhemos não é a única válida ou simplesmente possível, e que, por conseguinte, não devemos ficar cegos face às vantagens de outras fórmulas. Em segundo lugar, estas sociedades conseguiram um determinado número de coisas que nós ignoramos ou que já não sabemos fazer: como transmitir, sem brusquidão nem choques, a cultura ao longo das gerações e, principalmente, viver em boa relação com o meio natural, respeitando-o. Estas sociedades preveem sem dúvida alguma um lugar especial para o ser humano, mas nenhuma o torna dono e senhor de criação, com liberdade para dispor do seu ambiente, sem se preocupar com as espécies vegetais e animais que destroi, e com o mundo que deixará aos seus descendentes. Depois da lição de sabedoria, podemos esperar delas uma lição de moderação. (Lévi-Strauss citado por Llobera, 1979, p. 100)

A história ambiental no Brasil é um campo de pesquisa que se encontra em fase de consolidação e, potencialmente, pode contribuir para a 
análise dos ciclos agrários brasileiros em suas principais características, a saber: latifúndio, monocultura, exploração humana, injustiças sociais, violência no campo, concentração de renda, compromissos externos e dívidas socioambientais internas, degradação ambiental, extinção da biodiversidade (flora e fauna) e diminuição drástica da capacidade de resiliência dos agroecossistemas, diminuição do patrimônio natural, dilapidação dos recursos naturais (solo, água) e postura genocida, no que se refere à sociodiversidade. Assim, por intermédio de instrumental bibliográfico podemos levar à conscientização dos atores sociais envolvidos com a agricultura, de modo a provocar transformações na realidade agrária ao buscar, nas práticas agroecológicas, estratégias socioambientais capazes de resgatar as históricas possibilidades "perdidas". Como afirma Drummond (1991, p. 195):

Quero sugerir que a história ambiental pode contribuir nos próximos anos para que se atinja um meio termo entre os "ciclos estanques" e os "ciclos abstratos". A melhor agenda para um possível grupo de historiadores ambientais talvez seja retomar os temas dos ciclos econômicos da história colonial e independente do Brasil, o enclave ambiental. O objetivo seria identificar, em escala regional e local, que tipos de sociedades se formaram em torno de diferentes recursos naturais, que permanência tiveram essas sociedades e que tipo de consequências elas criaram para os seus ambientes sustentarem outro tipo de sociedade.

Podemos, por fim, afirmar que um dos principais objetivos da história ambiental é, fundamentalmente, entender a germinação e o florescimento dos processos civilizatórios na fluidez das épocas e nos mosaicos ecossistêmicos de nosso país - enfim, a história ambiental é uma reflexão sobre a memória das paisagens. Por outro lado, a geografia pode ser compreendida como um documento histórico no qual imprimimos nossas práticas culturais. Assim, portanto, o estudo histórico ambiental das relações entre a sociedade brasileira e o seu território são essenciais para a avaliação, planejamento e gestão sustentável do espaço agrário.

\section{A sustentabilidade dos agroecossistemas familiares: uma abordagem geo-histórica}

Precisamos conceber os sistemas de produção da agricultura familiar como protagonistas insubstituíveis para a gestão sustentável dos recursos socioambientais (sociodiversidade, biodiversidade, água, solo etc.) 
gerando mecanismos de avaliação da potencialidade dos agroecossistemas. Estudos históricos ambientais podem apontar a necessidade de as políticas públicas priorizarem projetos agrofamiliares viáveis economicamente, ecologicamente prudentes e comprometidos com as demandas sociais. Pois, no pensamento de Shumacher (1973, p. 32),

embora até pequenas comunidades sejam às vezes culpadas de provocar erosão grave, geralmente por ignorância, essa é insignificante comparada às devastações causadas por grupos gigantescos motivados por ganância, inveja e ânsia de poder. É obvio, além disso, que homens organizados em pequenas unidades tomarão mais cuidado do seu pedaço de terra ou de outros recursos naturais do que companhias anônimas ou governos megalomaníacos que fingem para si mesmos que o universo inteiro é sua legítima presa.

Por outro lado, segundo Morin, as relações das sociedades com o seu meio natural deve ser pautada pelo pensamento sistêmico, complexo e dialógico. Em suas palavras,

a história da humanidade é de interação entre a biosfera e a espécie humana. A interação intensifica-se com o desenvolvimento da agricultura, que tem profundo efeito nos ecossistemas do mundo. Cada vez mais ela se transforma num diálogo (numa relação ao mesmo tempo complementar e antagônica) entre a natureza e a espécie humana. (Morin, 1991, p. 107)

As práticas agroecológicas em unidades agrofamiliares configuram um promissor binômio para as políticas públicas comprometidas com as dimensões de sustentabilidade social, econômica, ambiental, cultural, geográfica ou territorial. Porém, vivemos a era da pesquisa egoísta, cujo objetivo principal é priorizar monoculturas em grandes áreas para exportação, visionando apenas os vultosos ganhos monetários. Já os recursos financeiros destinados aos institutos de pesquisa voltados para sistemas de produção agrícola familiar pautados no conceito de sustentabilidade geralmente são insuficientes para que se obtenham bons resultados, evitando desastres socioambientais. É importante lembrar que o futuro de milhões de seres humanos depende, em larga medida, das pesquisas elaboradas por esses centros. Nas palavras de Schumacher (1973, p. 101-102),

podemos dizer que a administração da terra pelo homem deve ser orientada primordialmente para três metas: saúde, beleza e permanência. A quarta meta - a única aceita pelos técnicos -, a produti- 
vidade, será alcançada quase como um subproduto. A concepção cruamente materialista vê a agricultura como "essencialmente voltada para a produção de alimentos”. Um enfoque mais aberto vê a agricultura como tendo de preencher no mínimo três tarefas:

- manter o homem em contato com a natureza viva, de que ele é e continua a ser uma parte muito vulnerável; - humanizar e enobrecer o habitat mais vasto do homem; e - proporcionar os alimentos e outros materiais necessários a uma vida condigna. Não creio que uma civilização que reconhece somente a terceira dessas tarefas, e que a busque com tamanha implacabilidade e violência a ponto de as outras duas serem não só negligenciadas como sistematicamente contra-atacadas, tenha a menor probabilidade de sobreviver em longo prazo.

É importante esclarecer que a história ambiental também é uma reflexão econômica e social, construída à luz das contradições presentes no processo estabelecido entre sociedade e natureza, ao longo do tempo. Por outro lado, a história econômica deveria avaliar as alterações materiais nas estruturas de consumo e pesquisar sua viabilidade e impactos ambientais, ou seja, suas externalidades. Ao contrário disso, a história econômica produz uma série de cifras sobre a produção fabril ou sobre o produto nacional bruto das diversas economias que se inserem nos mecanismos de crescimento econômico. Já a história ambiental interpreta os conflitos socioambientais causados pelo acesso desigual aos recursos naturais. Preocupa-se, ainda, com os limites depuradores e com as ocorrências de colapso da natureza no tempo e no espaço. Como afirma Altieri (2002, p. 85-87),

O agroecossistema é a unidade ecológica principal. Contém componentes abióticos e bióticos interdependentes e interativos, por intermédio dos quais se processam os ciclos de nutrientes e o fluxo de energia.[...] Os agroecossistemas tendem à complexidade. Eles podem passar de formas mais simples para estados mais sofisticados. Entretanto, essa transformação direcional é inibida na agricultura moderna pelas monocultoras, caracterizadas por baixa diversidade e baixo nível de complexidade.

A discussão agroecológica, por sua vez, não deve perder de vista as dimensões socioeconômicas da nossa realidade agrária, já que propostas como a mera substituição dos agroquímicos, sem o enfrentamento de questões fundamentais como a reforma agrária no Brasil, dificilmente reverterão o modelo agrícola socioambientalmente predatório que reina 
entre nós. É preciso perceber que as crises socioambientais geradas pelos latifúndios monocultores no Brasil são condicionadas pelas circunstâncias históricas e não serão equacionadas apenas com a adequação de suas práticas aos princípios ecológicos, por mais essencial que isto seja. Ainda de acordo com Alier (p. 243),

em primeiro lugar, não temos instruções genéticas a respeito do consumo exossomático da energia e materiais; em segundo lugar, a demografia humana, apesar de seguir a curva logística característica de qualquer população, é uma demografia "consciente", que depende de estruturas sociais, da liberdade social das mulheres; finalmente, a territorialidade humana e a distribuição geográfica da humanidade, as migrações e as proibições das migrações, não são fatos de "natureza" nem se podem explicar de forma convincente com analogias etológicas. Portanto, longe de "naturalizar" a história, a introdução da ecologia na explicação da história humana "historiciza" a ecologia, já que a ecologia humana (ou seja, as relações entre as sociedades humanas e a natureza) não é entendida se não entendermos a história dos humanos e seus conflitos. A ecologia não é nenhum telão de fundo de longue durée, mas parte da nossa história.

Um dos fatores fundamentais que explicam a diversidade dos sistemas socioculturais é a multiplicidade de habitats que a terra apresenta. Portanto, é conveniente incorporarmos o conceito de agroecossistema para o exercício da história ambiental dos ciclos agrários brasileiros, com a expectativa de que ele possa auxiliar o processo de reflexão agroecológica no Brasil, buscando a consolidação de sistemas de produção familiares sustentáveis.

Já nas palavras de Gliessman (2000, p. 74-75),

a manipulação e alterações humanas dos ecossistemas, com o propósito de estabelecer uma produção agrícola, tornam os agroecossistemas muito diferentes dos ecossistemas naturais. Ao mesmo tempo, contudo, os processos, estruturas e características dos ecossistemas naturais podem ser observados nos agroecossistemas.

\section{O mesmo autor complementa que}

o desafio de criar agroecossistemas sustentáveis é o de alcançar características semelhantes às de ecossistemas naturais, mantendo uma produção para ser colhida. No trabalho em direção á sustentabilidade, o responsável por qualquer agroecossistema se esforça, tanto quanto possível, para usar o conceito de ecossistema no dese- 
nho e manejo do agroecossistema. Finalmente, um agroecossistema que incorpore as qualidades de ecossistema natural de resiliência, estabilidade, produtividade e equilíbrio assegurarão melhor a manutenção do equilíbrio dinâmico necessário para estabelecer uma base ecológica de sustentabilidade. (p. 79)

A abordagem histórico-ambiental dos ciclos agrários permite a análise de algumas das razões dos desequilíbrios econômicos regionais e dos agudos desníveis sociais encontrados em nossa população, desvela as raízes históricas da degradação dos agroecossistemas e do comprometimento dos potenciais humanos e ecológicos na gestão sustentável dos recursos naturais, nos quadros geo-históricos. A esse respeito, compara Martinez (2006, p. 36-37):

Tal como a história rural francesa descortinou o mundo do camponês, os estudos da história ambiental no Brasil, podem proporcionar maior e melhor conhecimento de um passado tecnológico, desenvolvido secularmente pelas sociedades não-capitalistas, e adequado, por exemplo, à agricultura nos trópicos, ás indústrias domésticas e ao artesanato familiar. Fazer emergir universos culturais de caboclos, ribeirinhos, quilombolas, pescadores e indígenas, entre outros. Bem como as mudanças e permanências impulsionadas pelos contatos e intercâmbios derivados de cinco séculos de sociabilidades crescentes marcadas pela mercantilização das relações sociais, pela industrialização e pelas incessantes inovações tecnológicas. Pode-se assim, perceber as relações entre o centro e as periferias do capitalismo a partir de novas indagações, abrindo espaço para novas formulações interpretativas. A partir daí, retomar os grandes problemas intrínsecos à formação da sociedade e do estado no Brasil. O uso e ocupação de terras, as práticas agrícolas, os grandes projetos energéticos e de infra-estrutura, políticas públicas para o meio ambiente, movimentos sociais em defesa da natureza.

Nesta perspectiva, as estratégias tecnológicas devem considerar diferentes opções de manejo produtivo dos agroecossistemas familiares. A história das técnicas poderá ser de grande utilidade para a análise das opções, quanto ao emprego da força motriz humana e animal na adoção de formas de manejo apropriadas para a sustentabilidade dos sistemas de produção agrícolas familiares. É necessário levar em conta o papel das culturas como mediadoras entre os processos socioeconômicos e ambientais dos agroecossistemas familiares, pois toda a formação social rural desenvolve-se em estreita relação com o seu entorno natural e cultural. 
Artigo

\section{Considerações finais}

A construção dessa análise teórica teve o objetivo de destacar a contribuição da história ambiental dos ciclos agrários brasileiros para a reflexão agroecológica no Brasil. Desse modo, segundo Ávila (1995, p. 69), a pesquisa histórica tem por finalidade "reconstruir o passado sistemática e objetivamente, colecionando, avaliando, verificando e sintetizando evidências para estabelecer fatos e chegar a conclusões defensáveis, frequentemente, em relação a hipóteses particulares”.

Parte-se do pressuposto de que os agroecossistemas representam uma forma particular de ecossistema, abordando não apenas a produção, mas também a sua sustentabilidade socioambiental nas escalas local, regional e nacional, pois a resiliência e a estabilidade desses agroecossistemas não são determinadas apenas por variáveis bióticas ou ecológicas. Aspectos históricos (políticos, culturais e socioeconômicos) também determinam decisivamente a estrutura e os processos intrínsecos à organização espacial agrária.

Nas palavras de Porto Gonçalves citado por Becker (2002, p. 310311), "muitos dos problemas socioambientais com que nos defrontamos têm suas origens em processos sociohistóricos. Eis aí um novo desafio de escala: a temporal. Lembremo-nos do que o Prof. Milton Santos já nos apontara que o espaço é a acumulação de tempos" [grifos nossos].

A importância da temática dos ciclos agrários brasileiros começa, gradualmente, a ser reconhecida e discutida pela sociedade brasileira. Esta discussão é estimulada por inúmeros interesses, podendo ser destacados dois por representarem a tese e a antítese da proposta da pesquisa: o confessado interesse pelo agronegócio, objeto de estudo dos analistas de mercado (agrobusiness) e a preocupação com o patrimônio natural (ecossistemas e agroecossistemas). Este último geralmente é acompanhado pela preocupação social, com destaque para a reflexão sobre as políticas alimentares.

Em síntese, é preciso que sejam implementadas políticas públicas agrárias que gerem mecanismos de associativismo, reforma agrária, instrumentos de proteção dos ecossistemas e gestão sustentável dos agroecossistemas familiares, que integrem coevolutivamente a sociodiversidade com a biodiversidade, e que reconheçam e respeitem os direitos consuetudinários de determinadas comunidades tradicionais (indígenas, quilombolas, caiçaras entre outras). Por fim, não parece razoável destinar 
recursos públicos para financiar projetos ou programas que degradem os ecossistemas, tornem frágeis os habitats da biodiversidade e diminuam a diversidade cultural. Como lembra Guattari (2005, p. 54), "é preciso, mais uma vez, invocar a história! No mínimo pelo fato de que corremos riscos de não mais haver história humana se a humanidade não reassumir a si mesma radicalmente. Por todos os meios possíveis, trata-se de conjugar o crescimento entrópico da subjetividade dominante".

\section{Referências}

ALIER, Joan M. Da economia ecológica ao ecologismo popular. Blumenau (SC): Ed. da FURB, 1998. 402p.

ALTIERI, Miguel. Agroecologia: bases científicas para uma agricultura sustentável. Guaíba (RS): Ed. Agropecuária, 2002. 592p.

ÁVILA, Vicente F. de. A pesquisa na dinâmica da vida e na essência da universidade. Campo Grande: Ed. da UFMS, 1995. 154p.

BECKER, Berta K. Geografia e meio ambiente no Brasil. São Paulo: Hucitec, 2002.

DEL PRIORE, Mary; VENÂNCIO, Renato. Uma história da vida rural no Brasil. Rio de Janeiro: Ediouro, 2006. 223p.

DRUMMOND, José A. A História Ambiental: temas, fontes e linhas de pesquisa. Estudos Históricos, v. 4, n. 8, p. 177-197, 1991.

FAORO, Raimundo. Os donos do poder. Rio de Janeiro: Globo, 2001.

GLIESSMAN, Stephen R. Agroecologia: processos ecológicos em agricultura sustentável. Porto Alegre: Ed. da UFRGS, 2000. 653p.

GUATTARI, Félix. As três ecologias. São Paulo: Papirus, 2005. 56p.

HOLANDA, Sérgio B. de. Raízes do Brasil. São Paulo: Companhia das Letras, 2007. 220p.

LAMBERT, Jacques. Os dois Brasis. São Paulo: Cia. Editora Nacional, 1967. 277p.

LLOBERA, José R. As sociedades primitivas. Rio de Janeiro: Salvat, 1979. 143p.

MARTINEZ, Paulo H. História ambiental no Brasil: pesquisa e ensino. São Paulo: Cortez, 2006. 120p.

MORIN, Edgar. Salve a Terra. São Paulo: Globo, 1991. 208p.

OSÓRIO, Helen. História do Brasil-colônia: do pau-brasil ao açúcar, da mandioca às crises de subsistência. Ciência e Ambiente, v. 1, n. 19, p. 87-94, Santa Maria, 1999.

PÁDUA, José Augusto. Um sopro de destruição: pensamento político e crítica ambiental no Brasil escravista (1786-1888). Rio de Janeiro: Jorge Zahar, 2002. 318p.

PRADO Jr., Caio. História econômica do Brasil. São Paulo: Brasiliense, 1970. 354p. 
SCHUMACHER, E. F. O negócio é ser pequeno. São Paulo: Círculo do Livro, 1973. $271 \mathrm{p}$.

VIVAN, Jorge. Agricultura e florestas: princípios de uma interação vital. Guaíba (RS): Agropecuária, 1988. 208p.

ZEA, Leopoldo. Do colonialismo ao desenvolvimento dos povos pela universalização dos valores ocidentais. In: BIROU, Alain; HENRY, Paul-Marc. Um outro desenvolvimento. São Paulo: Vértice, 1987. p. 274-283.

Adão José Vital da Costa - Professor Assistente IV do Departamento de Geografia - UFPel - Doutorando em Sistemas de Produção Agrícola Familiar - FAEM.

José Geraldo Wizniewsky - Professor Adjunto do Departamento de Educação Agrícola e Extensão Rural CCR- UFSM - Santa Maria - RS.

Recebido para publicação em junho de 2009

Aceito para publicação em janeiro de 2010 